\title{
Exploring the Root of Chinese Traditional Garden Culture
}

\author{
CHEN Xiao-ming
}

China Bluestar Lehigh Engineering Corporation, Shanghai, China

xming-c@163.com

\begin{abstract}
By combing the occurrence and evolution process of Chinese traditional garden, analyzing classical gardens on the theme and artistic conception, exploring the origin of Chinese traditional garden culture with the help of the study of classical garden cases, the conclusion that the main root of traditional culture garden in Shanghai is putting forward.
\end{abstract}

Keywords: traditional garden, One Pond with Three Hills, Yingzhou Island, Three Lakes with Nine Peaks

\section{INTRODUCTION}

Chinese gardens are artistic places full of Chinese cultural elements for recreational activities. The Chinese characters “山 (Mountain)” and “水 (Water)” are among the earliest characters to be created. According to ancient Chinese prose, mountain effuse the earth's vitality to the surroundings, enabling the creatures to boom. The character of "山 (Mountain)" resembles the shape of a stone cliff, which was thought to be the highest point of a mountain by ancient people. Almost all Chinese characters relevant to a mountain can use Mountain as the radical. “水 (Water)" is thought to be the measurement of flatness. In the Five Elements Theory, Water represents the north. The character of Water resembles multiple rivers flowing together, with the vertical bar in the middle indicating the Yang $Q i$ hidden in the water. Almost all Chinese characters relevant to water can use Water as the radical. Ancient Chinese pursued the harmonious coexistence of human and nature. The ancient sightseers find beautiful natural landscape with mountains and rivers a good place to express feelings and emotions, so the landscaping of artificial hills and waters in a Chinese garden is often deemed as the externalization of owner's personality. ${ }^{[1]}$ Landscape culture, enriching with the cultural deposits and artistic concepts contained in mountains and waters, is an important part of Chinese traditional culture. Landscape is the theme of the garden, and One Pond with Three Hills is a specific landscape artistic conception demonstrating the ancient people's desire to live forever and live in coexistence with the nature. Adjacent to the East China Sea, Shanghai, a place that has Yingzhou Island and Three Lakes with Nine Peaks natural landscape in its territory, has inspired the origin of One Pond with Three Hills.

\section{GENERATION AND DEVELOPEMENT OF CHINESE GARDENS}

\subsection{You in Shang and Zhou Dynasties - the origin of Chinese gardens}

The earliest form of Chinese gardens had already existed in Shang and Zhou Dynasties, called “固(You)". The book of songs recorded that the king of Wu planned to build “直(You)”. You was a fenced animal farm managed by special personnel, which was a hunting place for nobles. It was also a place where animal sacrifices were carried out.

\subsection{Youyuan in the Spring and Autumn Period and the Warring States Period - the beginning of Chinese gardens}

By the Spring and Autumn and the Warring States period, You had more functions. Officials grew flowers and plants, and built supporting facilities inside the properties. The original You slowly transformed into “固 苑 (Youyuan)”. “直苑 (Youyuan)” was an enclosed ground for growing plants and keeping animals.

\subsection{Gongyuan in the Qin and Han Dynasties - the booming period for Chinese gardens}

During the Qin and Han dynasties, Youyuan was gradually turned into Gongyuan, which meant imperial garden. In this period, the thought of immortality 
governed the country, and the legends of fairyland widely spread among the public. History reported that Qin Shi Huang, the first emperor of China, sent some of his underlings to retrieve the elixir of life in the legendary East Sea Immortal Land. In the city Xianyang, Shaanxi, He also built an imperial garden called Orchid Pond as a miniature, imaginary immortal land in Orchid Pond Palace to express his yearn for the immortal land. In the imagination of ancient Chinese, the immortal land must have a beautiful scenery with mountains and waters, so the imperial gardens often took the form of a landscape garden with artificial hills and waters. Some of them combined with the natural landscape.

\section{ARTISTIC CONCEPTION OF CHINESE GARDEN CULTURE}

\subsection{Origin of One Pond with Three Hills}

The idea of One Pond with Three Hills was originated from ancient Chinese mythology. It was inextricably linked with Taoism, and was considered as a prominent feature of Chinese imperial gardens. One Pond referred to the Taiye Pond, a miniature of the East Sea in the east of Shanghai. Taiye Pond was in the west of the ancient city Chang'an, lay on the north of Jianzhang Palace and the southwest of Weiyang Palace. Three Hills referred to the mythical mountains floating on the East Sea, where the immortals lived in and the elixir of life grew. Those mythical mountains recorded in ancient books are Penglai, Fangzhang and Yingzhou.

\subsection{Booming of One Pond with Three Hills}

One Pond with Three Hills was first seen in the Orchid Pond Palace built by Qin Shi Huang. As recorded in the Annual of the Former Qin, "After the first emperor made Chang'an the capital, he diverted water from the Wei River to build the pond, and erected the miniatures of Peng and Ying Mountains inside."[2] The One Pond with Three Hills rule was formed in the Han Dynasty when the Jianzhang Palace was built. The One Pond with Three Hills rule in Jianzhang Palace is shown in Figure 1.

Since then, the idea of One Pond with Three Hills had gradually turned into the major layout pattern for ancient Chinese imperial palaces and private gardens, and evolved into a composition art exclusively owned by Chinese gardens.

\subsection{Classic Cases for One Pond with Three Hills}

\subsubsection{Four famous ancient gardens in China}

The Summer Palace, the Imperial Summer Resort, the Humble Administrator's Garden, and the Lingering Garden are renowned as the four most famous gardens in China. They are the only four classical gardens listed in the first batch of national key protected cultural relic units, hence they are widely recognized as the most excellent gardens in China. These four gardens all follow the core theme of One Pond with Three Hills.

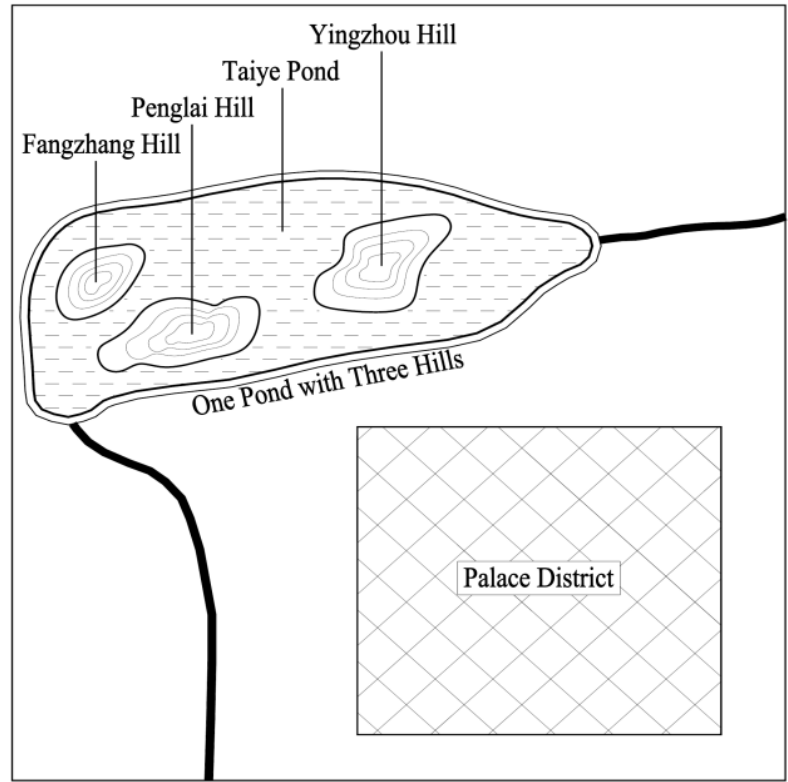

Figure 1 Sketch map of One Pond with Three Hills in Jianzhang Palace

\subsubsection{The Summer Palace - a classic example of One Pond with Three Hills in imperial gardens}

The Summer Palace is a typical example of Chinese imperial garden. The Kunming Lake inside the Palace is divided into three sub-lakes: West Lake, Yangshui Lake and South Lake. Inside each lake there is an island, forming the pattern of One Pond with Three Hills as shown in Figure 2.

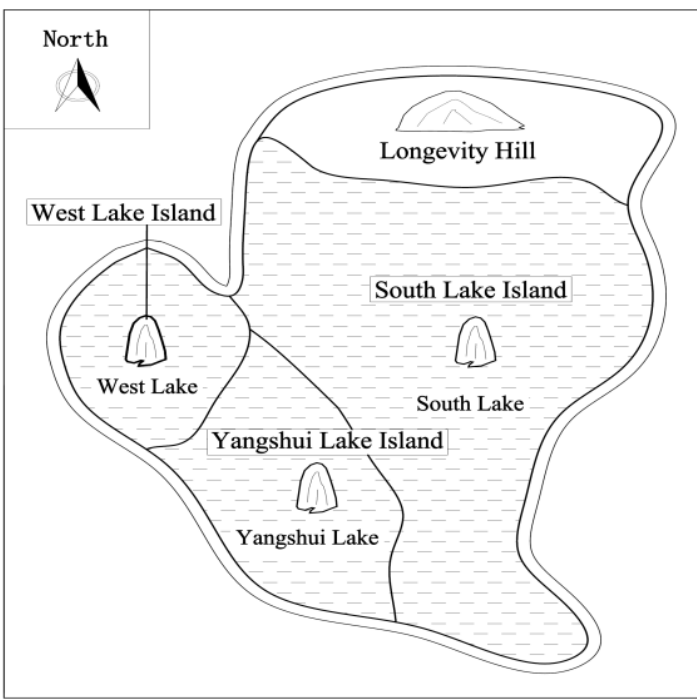

Figure 2 Sketch map of One Pond with Three Hills in the Summer Palace 


\subsubsection{Humble Administrator's Garden - a classic example of One Pond with Three Hills in private gardens}

The Humble Administrator's Garden is a typical example of Chinese private garden. The Taiye pond symbolizes the East Sea. In the middle of the Taiye pond there is an artificial island, on which erects three pavilions for landscape-viewing, called the Lotus Scent Pavilion, the Plum Forest Pavilion and the Autumn Frost Pavilion, symbolizing the three mythical mountains in the East Sea. The pattern of One Pond with Three Hills can be seen in Figure 3.

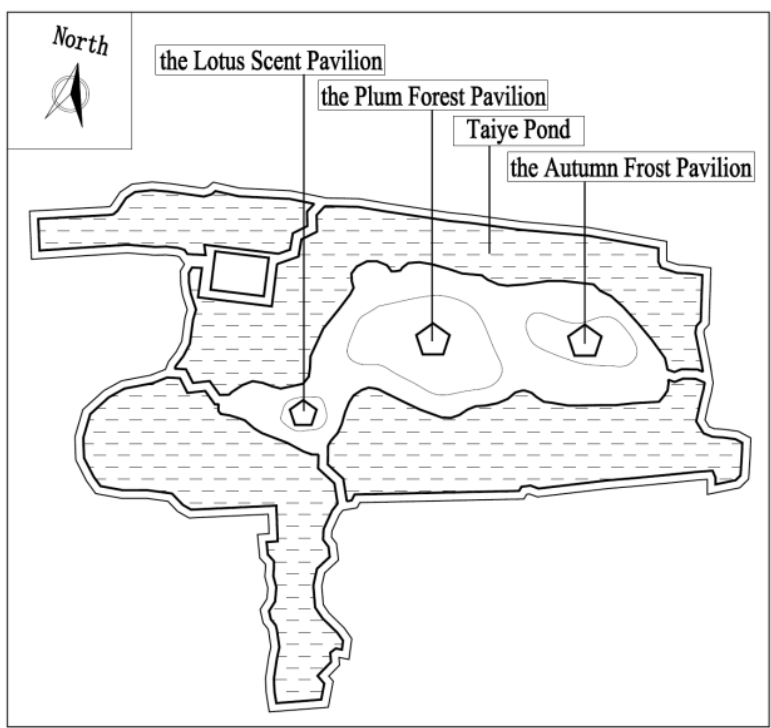

Figure 3 Sketch map of One Pond with Three Hills in the Humble Administrator's Garden

\section{THE ROOT OF THE POND-HILL CULTURE}

\subsection{Suiming - the predecessor of Chongming Island}

Chongming Island in Shanghai was formed during the expansion of the Yangtze River Delta. When water from Yangtze River entered the estuary, due to the gentler gradients and slower flow velocity, the sediment carried by the water gradually settled here. In the Qin Dynasty, Chongming Island had not formed yet. There were just some scattered sandbars below the surface of the river. With the ebb and flow of the tide, the sandbars sometimes were exposed, and sometimes disappeared. While the ancient people saw from a distance, the elusive image made them felt a fairyland existed there. So they named the place Suiming (崇明), a Chinese word often used to describe sneaky and looming objects. Their descendants mistook the character Sui (崇) for Chong (崇) because of the uncanny resemblance between them, so today people call the island Chongming Island.

\subsection{Qinwang Mountain — the relics of seeking immortals}

Not only did Qin Shi Huang build the One Pond with Three Hills in the Orchid Pond to express his longing for seeing immortals, or sent people to the East Sea to find the immortal land, the emperor also tried to find immortality personally. The Qinwang Mountain in today's Jinshan District, Shanghai, is recorded to be the site where Qin Shi Huang ascended to look out the immortal land in the East Sea. Figure 4 features the current appearance of Qinwang Mountain.

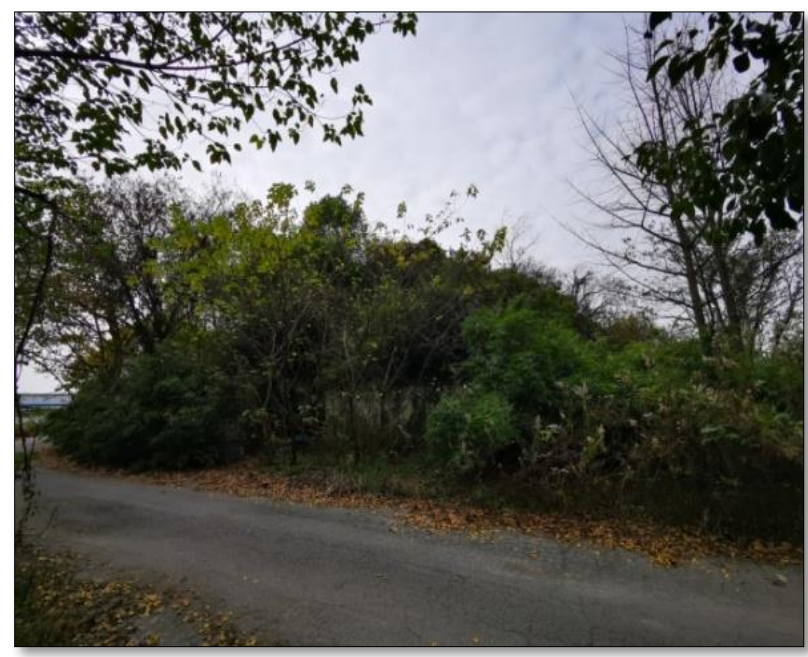

Figure 4 Qinwang Mountain

After Qin Shi Huang united the six Kingdoms, he traveled to this place and ascended the Qinwang Mountain in an attempt to see the legendary East Sea Immortal Land. As a sign in the Qin Mountain scenic spot reads, "Qin Mountain is also called Qinwang Mountain or Qin Station. Legend has it that Qin Shi Huang has ascended this mountain to watch the sea from here...Inside the mountain there are pits on the ground, which are thought to be built for the emperor's sedan chair." It is recorded that to get a better view of the sea, Qin Shi Huang cut down the trees in the front of Qinwang Mountain. The ochreous muds at the mountain were exposed, so the mountain was also called the Ochre Mountain. The location of Qinwang Mountain can be seen in Figure 5.

Apart from Qinwang Mountain, Qin Shi Huang also traveled to other sites in Shanghai on his journey to find immortals, such as Qin Pond, Qintang Bridge, Qinhuangchidao Avenue - the road where Qin Shi Huang was passing through, and the Sea-watching Pavilion. Records of the Qinhuangchidao Avenue can be found in ancient literature in the Song Dynasty. The following message was displayed at Shanghai Fengxian History Exhibition: "Qinhuangchidao Avenue was constructed for Qin Shi Huang to watch the sea. It extended from Zhelin in the south to Jiading in the north. At Huangpu, the middle point of the road, a dock was 
set up for boats sailing to Liuzhi."

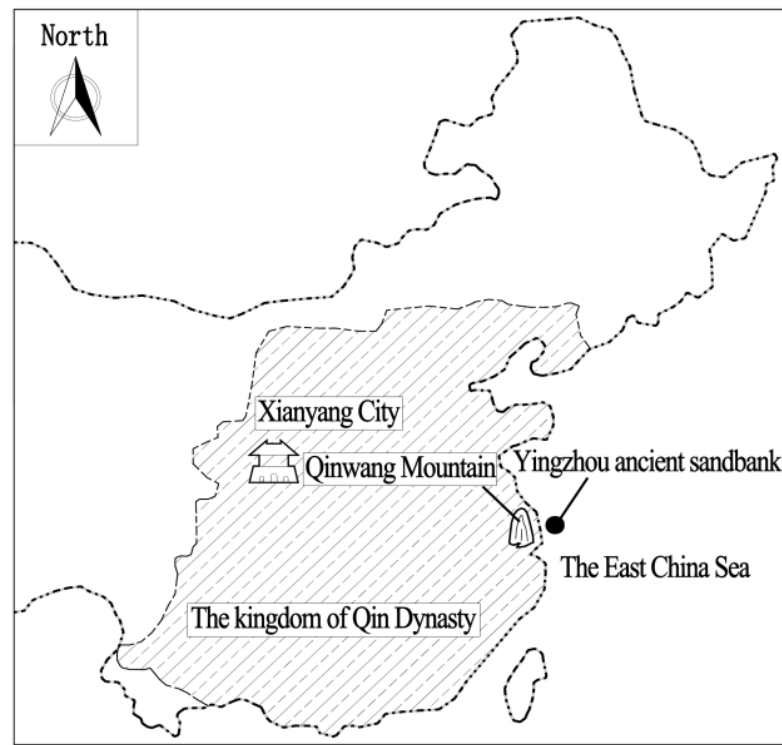

Figure 5 Location map for Qinwang Mountain in the Qin Dynasty

\subsection{Yingzhou in the East Sea - Chongming as its bestowed name}

In the Yuan Dynasty, He Yunfu, the governor of Chongming, led his people to surrender to the newly founded Ming Dynasty. Zhu Yuanzhang, the first emperor of the Ming Dynasty, wrote the Chinese characters of "East Sea Yingzhou" in calligraphy and presented them to the county in person. In fact, Chongming Island had been called Yingzhou for long. At the end of the Southern Song Dynasty, a horizontal inscribed board featuring the calligraphy of "Yingzhou on the Sea" written by a famous writer Wen Tianxiang in Song Dynasty was hanging over the door of Baoqing Temple on the island. The granted naming was inspired by the legendary Yingzhou Mountain on the East Sea Immortal Land.

\subsection{Three Lakes with Nine Peaks - the supreme pond-hill concept}

\subsubsection{Three Lakes and Nine Peaks}

Three Lakes, also called Songjun Three Lakes or Huating Three Lakes, referred to a series of small lakes located among Songjiang, Qingpu and Jinshan Districts of Shanghai, and Pinghu City of Zhejiang Province in ancient times. As written in Outline Gazetteer of Huating County, "The lake that is rounder at the end where the water come from is called the Round Lake; as it gets near the bridge, the broader lake is called the Large Lake; the lake extends for 50 kilometers upstream is called the Long Lake."

Nine Peaks, also called Nine Peaks Among the
Clouds, Songjiang Nine Peaks, or Songjun Nine Peaks, referred to nine peaks located in Songjiang District, Shanghai. They are Fenghuang Peak, Lubao Peak, She Peak, Xilin Peak, Xue Peak, Ji Peak, Hengyun Peak, Gan Peak, and Kun Peak. The term Nine Peaks was first seen in Ling Yan's Poems on Nine Peaks during the Song Dynasty. Ling wrote nine poems for nine peaks respectively.

\subsubsection{Three Lakes with Nine Peaks}

The Three Lakes with Nine Peaks layout of Shanghai in ancient China was determined by its geographical and cultural environment. To begin with, in terms of the geographical environment, Shanghai was adjacent to the immortal land in the East Sea. There were many mountains and lakes in here, and the Chongming Island was considered as a fairyland. Secondly, in terms of the cultural environment, landscape literature had been flousrishing in Shanghai, where literati were always willing to write poems for the scenery. Furthermore, the name "East Sea Yingzhou" given by an emperor convinced the public that Chongming Island was the immortal land Yingzhou.

In Chinese traditional culture, the Chinese character “三 (Three)” or “九 (Nine)” represents more than just the actual number 3 or 9 . The character "三 (Three)" is used to describe the complement of etiquette, things that too many to be counted, and the source of all things. The character “九 (Nine)" has connotations of the Heaven, the natural law, the paramountcy, the excessive proportion of Yang, the upward tendency, the abundance, the ultimate limit state, and the auspiciousness. ${ }^{[3]}$ By considering the matching of pond and hill in One Pond with Three Hills and the artistic conception of landscape, the ancient Chinese create Three Lakes with Nine Peaks - the supreme pond-hill concept.

In fact, there were more than nine peaks in the region. According to Records among the Clouds by Shaoxi in the Southern Song Dynasty, there are 18 peaks in the region, including Ji Peak, Dian Peak, etc. ${ }^{[4]}$ Besides, dozens of lakes can be found, but only three of them were selected and matched with the nine chosen peaks to create the supreme model of One Pond with Three Hills. The woodblock printing Three Lakes with Nine Peaks from the Ming Dynasty is shown in Figure 6.

By combining the legend of East Sea Immortal Land, the bestowed name East Sea Yingzhou of Chongming Island, the pond-hill culture in Three Lakes with Nine Peaks, and the relics of Qin Shi Huang seeking immortals, a complete picture of the pond-hill culture in the Ming Dynasty is formed, which can be seen in Figure 7. 


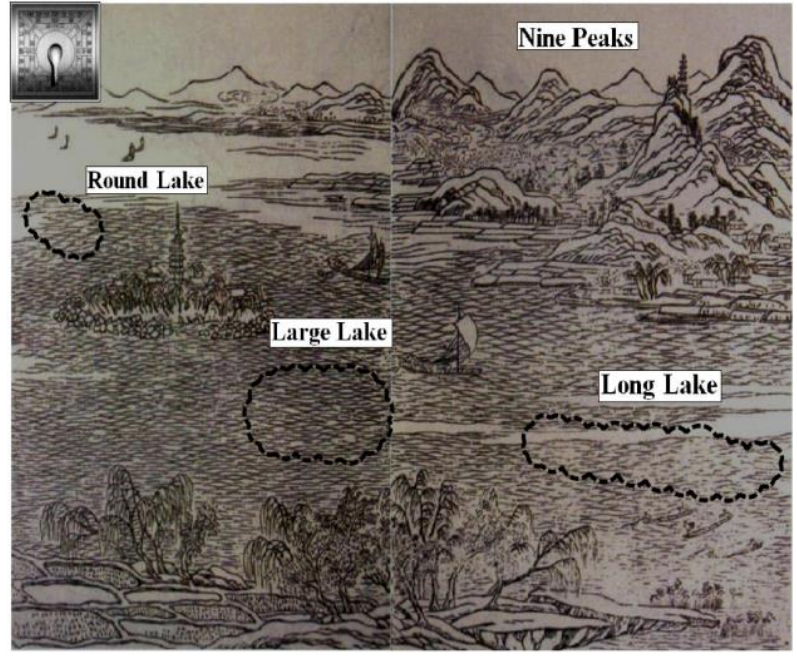

Figure 6 Three Lakes with Nine Peaks in Printings of Famous Mountains, a woodblock printing collection from the Ming Dynasty

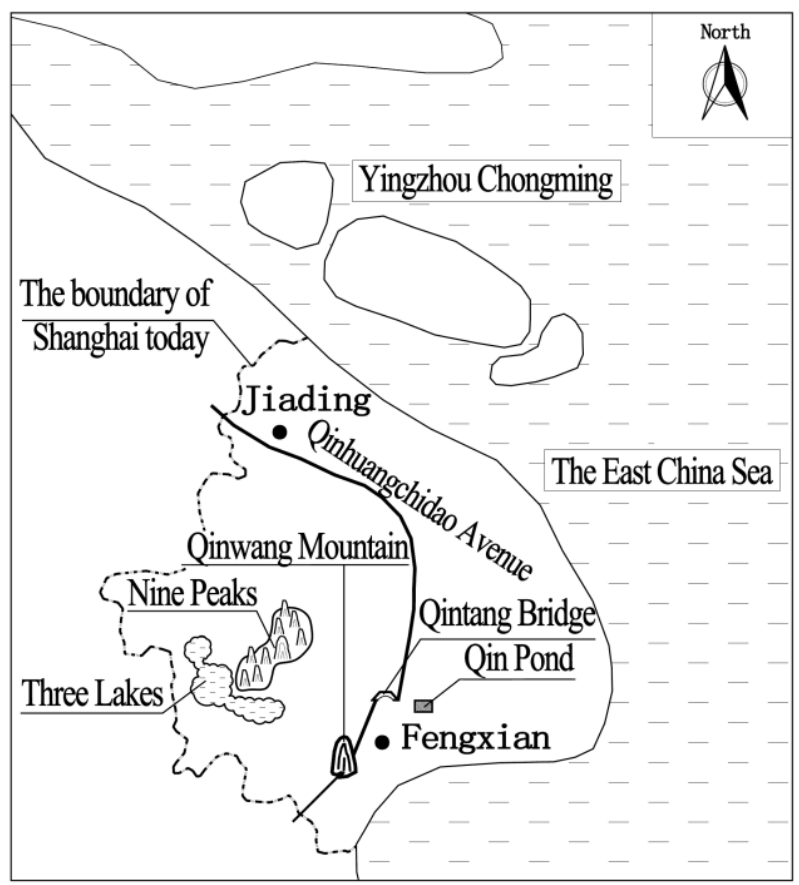

Figure 7 Picture of the pong-hill culture in the Ming Dynasty

\section{CONCLUSIONS}

As we look back upon the evolution of Chinese gardens, the following conclusions can be drawn:

(1) Chinese gardens were originated from animal farms, then transformed into imperial gardens. The pattern was followed by royal and private gardens after.

(2) The core element in Chinese garden culture was mountain and water, and One Pond with Three Hills was the basic artistic concept.

(3) The layout of One Pond with Three Hills was first seen in the Orchid Pond Palace in the capital city Chang'an during the Qin Dynasty. It was prospered in the imperial palaces of the Han Dynasty, and finally dominated the classical royal and private gardens.

(4) Shanghai is adjacent to the East Sea Immortal Land, and Chongming Island was bestowed with the name East Sea Yingzhou. Besides, Shanghai retains the relics of Qin Shi Huang seeking immortals, and the supreme pond-hill concept Three Lakes with Nine Peaks. Thus Shanghai can be seen as a root of Chinese garden culture.

\section{REFERENCES}

[1] WANFANG DATA, 2007. Research on the Concept of Heaven and Man in Chinese Urban Planning. http://d.wanfangdata.com.cn/thesis/ChJUaGVzaXN OZXdTMjAyMTAyMDESB1k5NDMwNzAaCGhp Z2loejh0.

[2] Wang, Z.J. (2014) Sea Pool in the Palace of Qin and Han Dynasties. Popular Archaeology, 2 : 50-54.

[3] Chen Y. (2019) Appearance of Iron Plate. In: American Academic Press, American Academic Press. (Eds.), Decoding Diagram on Boiling Seawater: Salt-making Method in Ancient China. American Academic Press, Salt Lake City. pp. $147-148$

[4] Shanghai Local Records Office, 2004. Toponymy of Shanghai. http://www.shtong.gov.cn/dfz_web/DFZ/ Info $?$ idnode $=70906 \&$ tableName $=$ userobject $1 \mathrm{a} \& i d=$ 73638 